\title{
Double-blind crossover clinical trial of pyridinolcarbamate in peripheral arterial disease (arteriosclerosis obliterans)
}

\author{
K. W. Walton, Gillian M. Craig, Patricia Prior, J. A. H. Waterhouse, and J. Skilton \\ From the Departments of Experimental Pathology, Social Medicine, and Surgery, University of Birmingham
}

A double-blind crossover clinical trial of pyridinolcarbamate, a bradykinin antagonist, was carried out in 33 men with peripheral vascular disease causing intermittent claudication. Results in 25 men are reported.

Peripheral circulation was assessed by measurement of work done before claudication in a step test, claudication point, and measurement of calf blood flow by venous occlusion plethysmography before and after exercise in a temperature-controlled environment. Performance in all three tests decreased during the placebo control period, making the evaluation of treatment difficult.

During the trial a significant improvement occurred in the step test. No dose-related drug effect was shown but a cumulative drug effect could not be decisively excluded. Performance in the step test correlated with alteration of external environmental temperature. Claudication point showed some improvement but only analysis over time produced a value significantly different from the combined control. Calf blood-flow increased to a small extent over treatment and time but did not exceed control values significantly.

The possible role of bradykinin in peripheral vascular disease in relation to the rationale of treatment with pyridinolcarbamate and the possibility of a seasonal variation in sensitivity to bradykinin (to account for the findings noted) are discussed.

The suggestion that pyridinolcarbamate, a bradykinin antagonist, may be beneficial in the treatment of atherosclerosis presents a novel and possibly valuable therapeutic approach. Initial clinical trials of the drug were promising (Shimamoto et al., 1970). It is widely used in Japan and South America and is being studied intensively in many parts of the world. Since the overall incidence and age of onset of atherosclerosis in Japan differs from that in Western populations (Shimamoto et al., 1966a), it was thought desirable to see whether pyridinolcarbamate would be effective in a British population. The chemical structure is 2,6-pyridine-dimethanol bis (N-methylcarbamate) (Fig. $\mathrm{I})$.

Some pharmacological properties of pyridinolcarbamate in experimental animals have been previously described (Shimamoto et al., 1966b; Willoughby, Lykke, and Ryan, 1969).

\section{Subjects and methods}

Tablets containing $250 \mathrm{mg}$ pyridinolcarbamate and identical placebo tablets containing lactose were supplied by the Banyu Pharmaceutical Co., Tokyo. Thirty-three men with intermittent claudication not severe enough to Received 7 August 1972. justify operation were selected. Patients with severe angina, diabetes mellitus, recurrent infection, cerebrovascular disease, or peptic ulceration, and those on anticoagulants were excluded. No patient had evidence of heart failure, renal or hepatic disease. The informed consent of the patients and of their general practitioners was obtained. No drugs known to affect peripheral blood vessels or clotting mechanisms were given, but any hypotensive or lipid-lowering regimens were continued.

\section{Design of trial}

The trial was conducted on an outpatient basis and was of a double-blind crossover design.

\section{PYRIDINOLCARBAMATE}<smiles>CNC(=O)OCc1cccc(COC(=O)NC)n1</smiles>

FIG. I Structure of pyridinolcarbamate. 
After a preliminary control period of 8 to 12 weeks, all patients received placebo for 4 weeks. The placebo control period was followed by 3 consecutive 8-week treatment periods, during which patients were divided into three treatment groups and received placebo, or I or $2 \mathrm{~g}$ pyridinolcarbamate daily in the sequence shown in Fig. 2.

The term 'placebo treatment' distinguishes placebo given during the double-blind section of the trial, from that given in the placebo control period.

In order to mask the change in dose, patients received two boxes of tablets packed appropriately, and took one tablet from each box 4 times daily. One box and the foil of its contained tablets was marked with a red line to prevent confusion. Eight or 9 patients a week began placebo tablets during 4 consecutive weeks in March 1970, and the trial was completed by October 1970.

Allocation of patients to treatment groups $\mathrm{Pa}$ tients stratified in respect of blood pressure, smoking habits, and disease severity were divided by random number tables into 3 treatment groups. Patients with hyperlipidaemia, including 6 taking clofibrate, were distributed randomly. For purposes of stratification, the blood pressure recorded with a mercury sphygmomanometer at the initial examination was used, and expressed as 'mean BP', i.e. (systolic + diastolic) $\div 2$. Disease severity was assessed on the basis of the mean work done in a step test during the control period. The patients were separated into two groups by the following dividing lines:- a mean BP of less than $125 \mathrm{mmHg}$ (low) of more than $125 \mathrm{mmHg}$ (high): a daily cigarette consumption of less than Io (light smoker) or more than Io (heavy smoker), and the ability to do less than $50 \mathrm{~kg} \mathrm{~m}$ of work (severe disease) or more than $50 \mathrm{~kg} \mathrm{~m}$ of work (moderate disease) in the step test. Table I shows the composition of the treatment groups at the time of final analysis (25 patients).

Patients attended fortnightly for 28 weeks. Biochemical profile, haemoglobin, total and differential white counts, and the serum level of the drug were measured during the placebo control period, and twice in each treatment period. The urine concentration of pyridinolcarbamate was measured at each visit, and serum lipids at week $O$ and 26. At each visit, patients were asked whether their legs were the same, better, or worse than at the last visit. At week 28, a standard questionnaire was

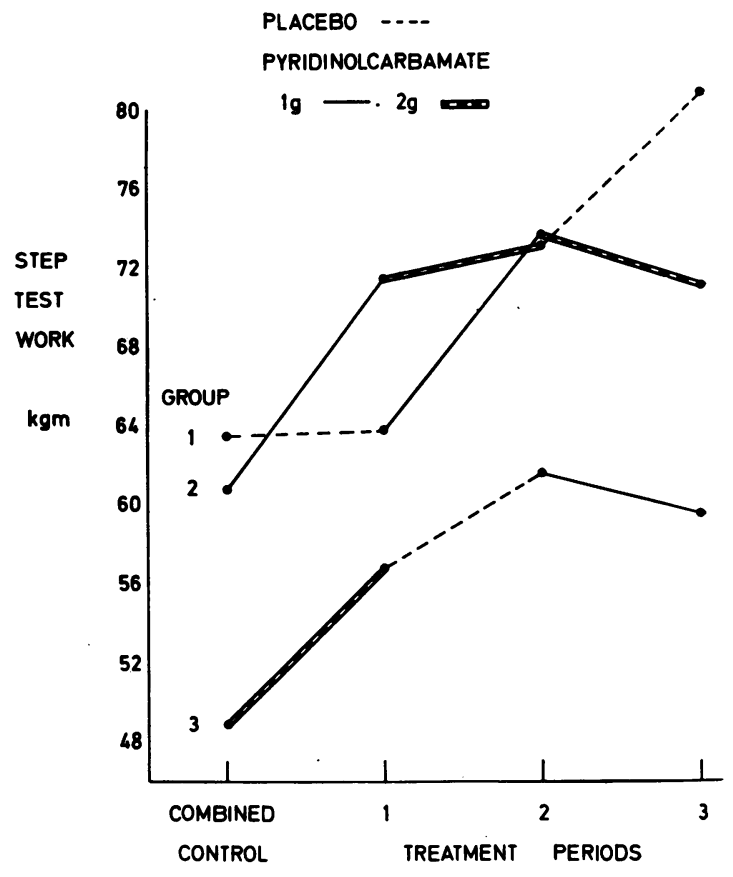

FIG. 2 Step test. Mean results analysed by treatment schedule groups.

used to record any change in symptoms or in smoking habits during the trial.

Assessment of peripheral circulation Four objective criteria were used, namely: digital palpation of leg pulses, work done before claudication in a step test, claudication point, and measurement of calf blood flow before and after exercise. The frequency and timing of observations is shown in Table 2. No smoking was allowed for one hour before appointments. Leg pulses were palpated when both patient and observer had been in a warm room $\left(\mathrm{N} 26-28^{\circ} \mathrm{C}\right)$ for 15 minutes.

Step test The patient rested for 20 minutes at $28^{\circ} \mathrm{C}$ and then stood under a height-measuring gauge, with

TABLE I Randomization of patients within treatment groups at final analysis

\begin{tabular}{|c|c|c|c|c|c|c|c|}
\hline & \multirow{2}{*}{$\begin{array}{l}\text { Total } \\
\text { patients }\end{array}$} & \multicolumn{2}{|c|}{ Smoking } & \multicolumn{2}{|c|}{ Blood pressure } & \multicolumn{2}{|c|}{ Disease severity } \\
\hline & & Light & Heavy & Low & High & Moderate & Severe \\
\hline Group I & 10 & 4 & 6 & 6 & 4 & 5 & 5 \\
\hline Group 2 & 8 & 5 & 3 & 3 & 5 & 4 & 4 \\
\hline Group 3 & 7 & 3 & 4 & 3 & 4 & 3 & 4 \\
\hline All groups & 25 & 12 & I3 & 12 & 13 & I2 & 13 \\
\hline
\end{tabular}


TABLE 2 Frequency and timing of observations

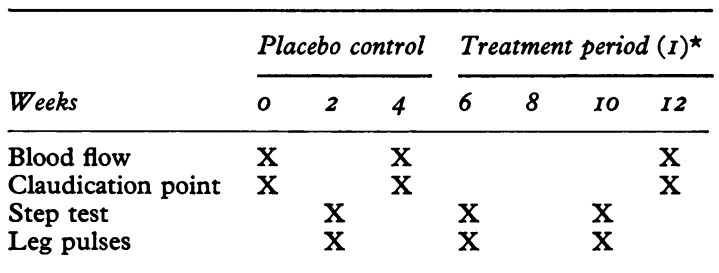

* Periods 2 (weeks $13-20$ ) and 3 (weeks 2 I-28) were similar to period $\mathrm{I}$.

the horizontal bar set $2.5 \mathrm{~cm}$ above his head. He then raised himself up and down until his head just touched the bar 36 times a minute in time with a metronome, until claudication began. The number of movements and the duration were noted. After a 20-minute rest the test was repeated and the mean of the two tests taken. The total work in kilogram metres causing claudication was calculated as follows. Body-weight $(\mathrm{kg}) \times$ distance lifted (metres) $\times$ times lifted.

Calf blood flow and claudication point Calf blood flow was measured by venous occlusion plethysmography (Whitney, 1953), with the patient lying supine, in an environment box at an air temperature between 25 and $26^{\circ} \mathrm{C}$. A two-strand mercury in rubber strain-gauge and bridge, made by Devices Instrument Company to the specifications described by Whitney, was used, with Devices pressure transducer and pen recorder. The strain-gauge was placed at midcalf level at the same distance below the tibial tuberosity on each occasion. It was mounted at a tension of $20 \mathrm{~g}$ with the strands $\mathrm{I} \mathrm{cm}$ apart, and was calibrated on the limb. The length of the strain-gauge at $20 \mathrm{~g}$ tension was determined using a wooden former of known circumference.

Four basal blood flows were recorded when the patient had been supine at $25-26^{\circ} \mathrm{C}$ for 20 minutes. Rhythmical calf muscle exercise, using a foot exerciser similar to that described by Shepherd (1950) was then started. By depressing a foot lever, the patient lifted a $5 \mathrm{~kg}$ weight vertically a standard distance, 27 times a minute in time to a metronome. Exercise was performed with knee and hip extended, movement being confined to flexion and dorsiflexion of the foot. The number of movements causing claudication (claudication point) was recorded and exercise was terminated 20 movements beyond this. Post-exercise hyperaemia was measured 15 and 45 seconds after stopping exercise, then at 30-second intervals for 4 minutes and then at 60-second intervals until 20 minutes had elapsed after exercise. The blood flows at 19 and 20 minutes were specified 'resting flows'. A standard exercise of $\mathbf{2 0}$ movements was then undertaken, and flows were measured 15 and 45 seconds after this. The following blood flows were recorded for analysis (a) basal flows, (b) peak flow after prolonged exercise minus basal flow, (c) resting flow, and (d) peak flow after standard exercise minus basal flow.
Biochemical methods Tests comprising a 'biochemical profile', namely serum glucose, creatinine, sodium, potassium, calcium, serum aspartate aminotransferase (SGOT), iron, uric acid, and cholesterol were measured by automated techniques (Whitehead, 1969). Serum lipids and lipoproteins (including ultracentrifugal analysis of the latter) were measured as previously described (Craig and Walton, 1972).

Serum and urine levels of pyridinolcarbamate and its metabolites were measured by thin-layer chromatography using a modification of a technique described by Jackson and Moss (1969).

\section{Results}

Results from 25 of the original 33 participants were used in the final analysis. Five sets of results were discarded because of unsatisfactory blood and urine levels of pyridinolcarbamate. One patient was withdrawn because of a cardiac arrhythmia, one because of diarrhoea, and one defaulted.

Results for the step test, claudication point, and blood flow were analysed. Digital palpation of leg pulses proved an unreliable method of assessing progress and the results were not used.

\section{Control values}

The mean values during the placebo control period were less than those of the control period of all tests, and the variance ratios (control: placebo control) were significantly high $(\mathbf{P}<0.05)$. Therefore in subsequent analyses, treatment period values were tested against both the control period value and a combined control value, this being the mean of control and placebo control values.

Results were analysed in relation to (A) treatment and (B) time. The mean results during each control and treatment period are shown in Table 3. The data were also analysed in terms of mean change in response, using for each patient the deviation from his own control or combined control value (see Tables 3 and 4).

\section{Analysis of results in relation to treatment}

A significant improvement in performance in the step test was apparent when mean treatment values were compared with the combined control (Table 3). However, no dose effect could be shown, and the placebo treatment mean exceeded that for $2 \mathrm{~g}$ pyridinolcarbamate. Claudication point improved during the treatment periods, but not significantly. Calf blood flow did not increase beyond control values with the exception of the mean peak flow after prolonged exercise on $2 \mathrm{~g}$ pyridinolcarbamate, but this was not significant when compared with the combined control. There was no change in basal blood flow or in 'resting' flow 20 minutes after pro- 
TABLE 3 Mean response in relation to: $A$, treatment, and $B$, time

\begin{tabular}{|c|c|c|c|c|c|c|}
\hline & \multirow{2}{*}{$\begin{array}{l}\text { Claudication } \\
\text { (movements) }\end{array}$} & \multirow{2}{*}{$\begin{array}{l}\text { Step test } \\
\text { (work in } \mathrm{kg} \mathrm{m})\end{array}$} & \multirow[t]{2}{*}{ Basal } & \multirow{2}{*}{$\begin{array}{l}\text { Calf blood flow } \\
\text { Prolonged ex. }\end{array}$} & \multicolumn{2}{|l|}{$(\mathrm{ml} / \mathrm{min} / 100 \mathrm{ml})$} \\
\hline & & & & & Resting & Standard ex.* \\
\hline Control & $48 \cdot 9$ & $6 \mathrm{I} \cdot 3$ & 2.57 & 5.41 & 3.02 & $5 \cdot 22$ \\
\hline Range & (21 to 83 ) & ( 25 to 167 ) & $(0.76$ to 6.90$)$ & $(0.14$ to $12 \cdot 89)$ & $(0.76$ to 6.90$)$ & $(0.15$ to 15.3$)$ \\
\hline Placebo control & $46 \cdot 2$ & $55 \cdot 2$ & 2.00 & $4 \cdot 48$ & $2 \cdot 62$ & 3.67 \\
\hline Combined control & $47 \cdot 5$ & $59 \cdot 3$ & $2 \cdot 28$ & $4 \cdot 94$ & $2 \cdot 83$ & $4 \cdot 47$ \\
\hline A Placebo treatment & $52 \cdot 9$ & $68 \cdot 3 t$ & $2 \cdot I I$ & $4 \cdot 60$ & $2 \cdot 67$ & 4.00 \\
\hline I g pyridinolcarbamate & $5 I \cdot 8$ & $69 \cdot 2 \ddagger$ & $2 \cdot 21$ & 5.09 & $2 \cdot 63$ & $4 \cdot 07$ \\
\hline $2 \mathrm{~g}$ pyridinolcarbamate & $56 \cdot 3$ & $67 \cdot 7 t$ & $2 \cdot 35$ & $6 \cdot 41$ & $2 \cdot 84$ & $5 \cdot 19$ \\
\hline \multirow{3}{*}{$\begin{array}{l}\text { B Period I } \\
\text { Period } 2 \\
\text { Period } 3\end{array}$} & $47 \cdot 2$ & $64 \cdot 1$ & $2 \cdot 11$ & 4.09 & 2.65 & $3 \cdot 43$ \\
\hline & $59 \cdot 0$ & $70 \cdot 0 \neq \varnothing$ & $2 \cdot 21$ & $5 \cdot 37$ & $2 \cdot 56$ & $4 \cdot 26$ \\
\hline & $55 \cdot 0$ & $71 \cdot 2 \neq \delta$ & $2 \cdot 35$ & $6 \cdot 73$ & $2 \cdot 94$ & $5 \cdot 56$ \\
\hline
\end{tabular}

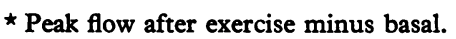

Difference from combined control significant: $+(P<0.05)$; $¥(P<0.01)$.

Difference from control significant: $\oint(P<0.05)$.

longed exercise. The mean resting flow exceeded the mean basal flow throughout the trial, and the difference did not diminish with treatment.

Analysis in terms of mean change in response (Table 4) showed that the step test performance decreased significantly during the placebo control period, but improved significantly during each treatment period. Claudication point improved but not significantly. Peak flow after standard exercise decreased significantly during placebo control and placebo treatment periods. All blood flow measurements on $2 \mathrm{~g}$ pyridinolcarbamate were greater than the combined control value, but the improvement was not statistically significant.

A comparison of results for each test within the three treatment groups suggested that randomization within the groups had been satisfactory and the treatment sequence had not significantly affected the response. However, Fig. 2 shows that in group I there was no difference in step test performance between the combined control and placebo treatment, whereas in groups 2 and 3 , in which placebo treatment followed high dosage ( $2 \mathrm{~g}$ ) of pyridinolcarbamate, improvement was apparently maintained on placebo.

Because of the possibility of some 'carry-over' effect during subsequent placebo treatment (Shimamoto et al., 1970) a further analysis was undertaken omitting the placebo treatment results. For each patient the combined control was subtracted from the combined $\mathrm{I} g$ and $2 \mathrm{~g}$ pyridinolcarbamate treatment values. Only the step test showed a significant mean difference in response of $+9.33 \mathrm{~kg} \mathrm{~m}$ $(\mathrm{P}<0.00 \mathrm{I})$ during treatment.

Individual results of this analysis showed that of the 25 patients, 22 had a positive response in the step test (range +0.2 to $19.9 \mathrm{~kg} \mathrm{~m}$ ); 16 in claudication point (range +0.5 to +38 movements); 15 in the peak calf blood flow after prolonged exercise (range +0.9 to $+4.9 \mathrm{ml} / \mathrm{min} / 100 \mathrm{ml}$ ), and $\mathrm{I2}$ in the

TABLE 4 Mean change in response in relation to treatment. Results expressed as mean deviation from control (C) or combined control (CC)

\begin{tabular}{|c|c|c|c|c|c|c|c|c|c|c|}
\hline & \multicolumn{2}{|c|}{$\begin{array}{l}\text { Claudication } \\
\text { (movements) }\end{array}$} & \multicolumn{2}{|c|}{$\begin{array}{l}\text { Step test } \\
\text { (work in } \mathrm{kg} \mathrm{m} \text { ) }\end{array}$} & \multicolumn{2}{|l|}{ Basal } & \multicolumn{4}{|c|}{$\begin{array}{c}\text { Calf blood flow }(\mathrm{ml} / \mathrm{min} / \mathrm{roo} \mathrm{ml}) \\
\text { Prolonged ex.* } \quad \text { Standard ex.*}\end{array}$} \\
\hline & $C$ & $C C$ & $C$ & $C C$ & $C$ & $C C$ & $C$ & $C C$ & $C$ & $C C$ \\
\hline $\begin{array}{l}\text { Placebo control } \\
\text { Placebo treatment } \\
\text { I g pyridinolcarbamate } \\
2 \text { g pyridinolcarbamate }\end{array}$ & $\begin{array}{r}-1 \cdot 8 \\
2 \cdot 3 \\
5 \cdot 0 \\
8 \cdot 6\end{array}$ & $\begin{array}{l}- \\
5 \cdot 7 \\
5 \cdot 4 \\
9 \cdot 5\end{array}$ & $\begin{array}{r}-6 \cdot 4 t \\
8 \cdot 3 t \\
7 \cdot 5 t \\
6 \cdot 2 t\end{array}$ & $\begin{array}{c}- \\
10.6 \dagger \\
9.8 \ddagger \\
8.5 \ddagger\end{array}$ & $\begin{array}{l}-0.57 \\
-0.46 \\
-0.36 \\
-0.22\end{array}$ & $\begin{array}{r}- \\
-0.19 \\
-0.08 \\
0.07\end{array}$ & $\begin{array}{r}-0.93 \\
-0.83 \\
-0.31 \\
1.07\end{array}$ & $\begin{array}{r}- \\
-0.43 \\
0.15 \\
1.56\end{array}$ & $\begin{array}{l}-r \cdot 80 \ddagger \\
-r \cdot 33 \dagger \\
-I \cdot 13 \\
-0.15\end{array}$ & $\begin{array}{r}- \\
-0.32 \\
-0.09 \\
0.94\end{array}$ \\
\hline
\end{tabular}

* Peak flow after exercise minus basal.

Significance levels: $\dagger P<0.05 ; \ddagger P<0.01$. 
peak flow after standard exercise (range $+0 \cdot 1$ to $+4.1 \mathrm{ml} / \mathrm{min} / 100 \mathrm{ml}$ ). In general, subjects did not show a consistent response for all four tests.

\section{Analysis of results in relation to time}

The analysis of data in relation to treatment showed no definite dose-related effect of pyridinolcarbamate. If the compound took longer to act than the 8 weeks allowed for each treatment period, an effect, including any carryover, might be reflected in the patients' performance in the third treatment period. To investigate this possibility, the data were rearranged and analysed by chronological sequence irrespective of dose. Analysis in terms of mean response (Table 3, Part B) showed a significant increase over both the control and combined control value for the step test alone $(P<0.01)$ during treatment periods 2 and 3. A similar tendency was shown for claudication point and peak calf blood flow after prolonged and standard exercise, but the changes were not significant.

Analysis in terms of mean deviation (Table 5) showed, in addition to an enhanced degree of significance for the step test results, that claudication point and peak calf blood flow after prolonged exercise increased significantly $(P<0.05)$ from the combined control value in periods 2 and 3 , respectively. Within broad limits all tests showed basically the same pattern over time: a decrease from control values during the first part of the trial, followed by a rise in the latter half.

Evaluation of seasonal variation effect Even if the improvement in performance during the latter months of the trial could perhaps be attributed to a cumulative drug effect, the decrease during the placebo control period still needed explanation, particularly since, for all tests, the significance of the change in response was due mainly to low values during this period. Discounting an adverse placebo reaction, ambient temperature was considered as a possible complicating variable. A mean ambient temperature for each calendar week was obtained from the records of Edgbaston Observatory, and this was compared with step test results.

Step test results were available for subgroups of patients during each calendar week, and these weekly means were plotted above the mean temperature for the corresponding week. Mean monthly step test results for all patients were also compared with mean temperature over the same four-week periods. The overall picture (Fig. 3) was of performance following temperature. When a correlation analysis was carried out on mean weekly values over the trial period (both variables in logarithms), a lag period of one week gave a correlation coefficient $(r=0.587, P<0.01)$ which was marginally higher than the values for lag periods of 2 to 8 weeks.

It was possible that a major temperature effect was masking a subordinate drug effect. To isolate a residual element which might correlate with drug dosage, the mean weekly performance value was subtracted from each patient's result for that specific week. The resultant values were then analysed in relation to treatment, but no residual drug effect could be demonstrated. Repeating the procedure with four-point moving averages of the weekly performance values (to allow for variation between the four subgroups on which they were based) gave a similar negative result. The residual values for each patient remained remarkably constant over the trial.

\section{Factors influencing response}

The effect of smoking habits, blood pressure, and serum cholesterol level on response were examined separately. Patients were classified into 'high' and 'low' groups for each factor on a basis similar to that used in the initial stratification, a level of 260 $\mathrm{mg} / \mathrm{roO} \mathrm{ml}$ being used for serum cholesterol. Results were analysed in terms of the deviation of

TABLE 5 Mean change in response in relation to time

Results expressed as mean deviation from control $(C)$ or combined control $(C C)$

\begin{tabular}{|c|c|c|c|c|c|c|c|c|c|c|}
\hline & \multicolumn{2}{|c|}{$\begin{array}{l}\text { Claudication } \\
\text { movements }\end{array}$} & \multicolumn{2}{|c|}{$\begin{array}{l}\text { Step test } \\
\text { (work in } \mathrm{kg} \mathrm{m} \text { ) }\end{array}$} & \multicolumn{2}{|l|}{ Basal } & \multicolumn{4}{|c|}{$\begin{array}{c}\text { Calf blood flow }(\mathrm{ml} / \mathrm{min} / 100 \mathrm{ml}) \\
\text { Prolonged ex. }{ }^{\star} \quad \text { Standard ex. }\end{array}$} \\
\hline & $C$ & $C C$ & $C$ & $C C$ & $C$ & $C C$ & $C$ & $C C$ & $C$ & $C C$ \\
\hline $\begin{array}{l}\text { Period I } \\
\text { Period } 2 \\
\text { Period } 3\end{array}$ & $\begin{array}{r}-1.0 \\
11.5 \\
5.6\end{array}$ & $\begin{array}{c}-0.08 \\
12.4 \dagger \\
8.5\end{array}$ & $\begin{array}{c}2 \cdot 3 \\
8 \cdot 5 \ddagger \\
11 \cdot 2 \ddagger\end{array}$ & $\begin{array}{l}4.6 \\
10.85 \\
13.5 \ddagger\end{array}$ & $\begin{array}{l}-0.34 \\
-0.48 \\
-0.22\end{array}$ & $\begin{array}{r}-0.05 \\
-0.20 \\
0.06\end{array}$ & $\begin{array}{r}-I \cdot 36 \\
-0.04 \\
I \cdot 30\end{array}$ & $\begin{array}{c}-0.86 \\
0.43 \\
I \cdot 7 I^{\star}\end{array}$ & $\begin{array}{c}-\mathrm{r} .85 \ddagger \\
-0.98 \\
0.21\end{array}$ & $\begin{array}{r}-0.76 \\
0.05 \\
1.23\end{array}$ \\
\hline
\end{tabular}

* Peak flow after exercise minus basal.

Significance levels: $+P<0.05 ; \ddagger P<0.01 ; \$ P<0.001$. 


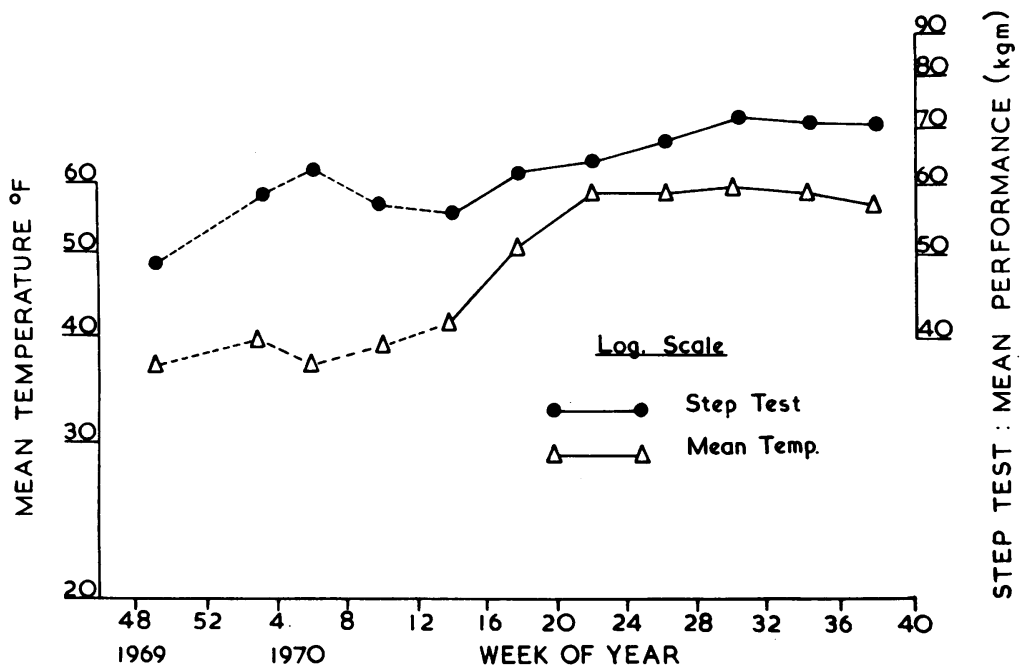

FIG. 3 Mean monthly step test performance with mean temperature for corresponding months. Control period indicated by dotted line. Step test results, mean of 22, 15, 24, and 15 patients for first 4 points in control period, and 25 patients throughout treatment period.

each patient from his own control for each factor in the step test, claudication point, and peak calf blood flow after prolonged exercise.

For all three tests the light smokers had a greater positive mean deviation than the heavy smokers, but the results were neither statistically significant nor clearly related to pyridinolcarbamate treatment. Neither cholesterol nor blood pressure levels had any consistent or significant effect on tests.

\section{Effect on coronary heart disease}

Eleven patients had electrocardiographic and/or clinical evidence of coronary artery disease before treatment. In 5 patients with angina it was unchanged subjectively in 4 and increased in $\mathrm{r}$. The electrocardiogram did not change in ro out of II patients, but one developed coupled ventricular ectopic beats after taking I $\mathrm{g}$ pyridinolcarbamate and treatment was withdrawn.

\section{Side effects}

Four patients developed diarrhoea on the $2 \mathrm{~g}$ dose. In one the diarrhoea was associated with nausea, anorexia, epigastric discomfort, and the passage of mucus rectally, and treatment was stopped. In 2 cases it was accompanied by mild depression, and in a third by early waking.

One patient with a past history of depression, having been well during the placebo control period, became depressed on $2 \mathrm{~g}$ pyridinolcarbamate daily, and suicidal during the subsequent placebo treatment. The depression improved on amitriptyline and did not recur when I $g$ pyridinolcarbamate was resumed. His results were excluded.

One patient developed haematuria and an increase in SGOT while on $2 \mathrm{~g}$ and was found to have a papilloma of the bladder.

\section{Biochemical and haematological results}

The haemoglobin, total and differential white count remained within normal limits during treatment, as did the serum albumin, globulin, sodium, potassium, calcium, and SGOT (with the one exception noted above).

Six patients had a raised serum uric acid and five a blood urea above $40 \mathrm{mg} / 100 \mathrm{ml}$. These abnormal values were unchanged during the trial.

No consistent changes in total cholesterol between week $O$ and 26 were observed between two laboratories, and values in groups $I$ and 3 (on pyridinolcarbamate week 26) were not significantly different from those in group 2 (on placebo week 26). The flotation factor (Sf) 0-20 cholesterol in all groups was lower at week 26 than at week 0 , the mean difference being $30 \mathrm{mg} / 100 \mathrm{ml}$ in groups $\mathrm{I}$ and 3 and $26 \mathrm{mg} / \mathrm{ro0} \mathrm{ml}$ in group 2. A small but insignificant rise in Sf 20-400 cholesterol occurred in all groups.

\section{Assessment of subjective changes}

At week 28, patients were asked whether their 
symptoms were better, unchanged, or worse during treatment, and whether the change, if any, occurred at the beginning, middle, or end of the trial. Of the 25 final participants, 16 felt better, 8 were unchanged, and I felt worse during treatment. Of the I6 who improved subjectively, Io felt best at the end, 2 in the middle, 3 from the midpoint of the trial onwards, and I did not answer this point. When told that three doses of drug had been tested all expressed surprise.

\section{Blood and urine drug levels}

The mean blood level of pyridinolcarbamate on $\mathrm{I} g$ daily was $9.4 \mu \mathrm{g} / \mathrm{ml}$, and on $2 \mathrm{~g}$ daily was 17.3 $\mu \mathrm{g} / \mathrm{ml}$. The mean urine level of pyridinolcarbamate and its metabolites was $56.7 \mu \mathrm{g} / \mathrm{ml}$ on I $\mathrm{g}$ daily, and $6 \mathrm{I} \cdot 4 \mu \mathrm{g} / \mathrm{ml}$ on $2 \mathrm{~g}$ daily.

\section{Discussion}

\section{Assessment of effect of treatment}

Assessment of the efficacy of medical treatment of arteriosclerosis obliterans is notoriously difficult because patients vary in the nature and extent of spontaneous progression of their signs and symptoms. Longitudinal studies by serial arteriography have, in most instances, shown either no improvement or gradual worsening of stenotic occlusions affecting the main arteries of the legs (Silbert and Zazeela, 1958; Dawson and Raphael, 1968). Arteriography was not used in the present study because of the known risks of this procedure (Chamberlain and Gleeson, 1965).

On the other hand, evaluations of function by flow measurements, ${ }^{133} \mathrm{Xe}$ clearance, or venous occlusion plethysmography (Bloor, 196I; Tillgren and Lund, 1967; Bollinger, Simon, and Mahler, 1969) have shown that spontaneous improvement can occur, presumably reflecting a variable capacity to form a collateral circulation.

A striking and unexpected finding in the course of the present study was the correlation found between functional capacity and external environmental temperature. The influence of this effect upon evaluation of pyridinolcarbamate merits discussion.

\section{Rationale for treatment of vascular disease with pyridinolcarbamate}

It is not known whether bradykinin plays a significant role in atherogenesis, and its importance in peripheral circulatory physiology is uncertain. Plasma kininase activity is low in arteriosclerosis, suggesting a low rate of kinin destruction (Dedichen and Vystyd, 1969). It has been suggested (Shima- moto et al., 1970) that pyridinolcarbamate may influence atherosclerosis by effects on endothelial permeability and on the arterial wall microcirculation.

In this regard, it is now established that plasma proteins permeate arterial walls, probably by a process of ultrafiltration that is influenced by blood pressure and changes in endothelial permeability. The entrapment in the intimal gel of low-density lipoproteins during the passage of plasma through the wall initiates the formation of atherosclerotic plaques (Walton, 1969). Since pyridinolcarbamate partially inhibits the permeability effects of the kinins and kinin-forming enzyme kallikrein (Lykke, Willoughby, and Kosche, 1967), it seemed possible that the compound might diminish oedema formation and reverse altered permeability where bradykinin was involved.

Further work is required to establish whether pyridinolcarbamate antagonizes the effect of bradykinin on the human microcirculation and, if so, whether the haemodynamic changes are beneficial. Intra-arterial bradykinin dilates both small and large arteries and increases reactive hyperaemia after arterial occlusion (Eriksson, 1969), while a reduction in reactive hyperaemia during pyridinolcarbamate treatment has been reported (Pratesi, 1972). Changes in osmolarity (Mellander et al., 1967) and of $\mathrm{K}$ ions (Kjellmer, 1965) are regarded as important factors in the mediation of postexercise hyperaemia, but it is thought that bradykinin may also contribute (Burch and DePasquale, 1963). Despite this, it seemed justifiable to test the response to a bradykinin antagonist by assessing postexercise hyperaemia. No significant change was found.

On the other hand, some effect was noted in tests in which the end-point was determined by discomfort due to muscle pain (step test, claudication point). Rodbard and Pragay (I968) have postulated that during a muscle contraction a metabolite is produced which diffuses into the extracellular space where a specific concentration of the metabolite in contact with pain receptors causes ischaemic pain. On this basis the results noted with pyridinolcarbamate might be ascribed to decreased production or release of metabolite (by its effect on membrane permeability) or direct antagonism of the effect of the metabolite on pain receptors. It is not known whether bradykinin itself produces muscle pain, or whether bradykinin antagonists, in this sense, behave as analgesics. By analogy, it has been suggested that the analgesic effect of aspirin may be due to an action whereby it blocks the release of an intermediary vasoactive substance produced in response to bradykinin (Piper and Vane, 1969).

The functional tests in our patients were all 
undertaken in a temperature-controlled environment. Nevertheless, functional capacity correlated with the external ambient temperature. Seasonal changes in bradykinin sensitivity have been shown in the rabbit and rat (Sternieri et al., 1969). If a similar seasonal variation in bradykinin sensitivity occurs in man, it could influence the response both to endogenous bradykinin and to a bradykinin antagonist, such as pyridinolcarbamate. The effect this may have had on our results is a matter for conjecture. However, it is of some interest that the nociceptive effect of intra-arterial bradykinin in rabbits was found to be least between April and July (Sternieri et al.), the period when step test performance improved in our patients.

The objective of this trial was to attempt to confirm the results of Shimamoto et al. (1970) who ascribed the improvement in claudication in 80 per cent of their patients to pyridinolcarbamate. Though there may have been differences in the severity or natural history of the condition between the populations tested, this cannot entirely explain the disparity in results. In our series, though a significant improvement occurred in the step test, no dose-related drug effect could be demonstrated. The results do not decisively exclude a cumulative drug effect, but the fact that claudication point and step test values were decreasing during the latter weeks of the trial throws doubt on the possibility. The proposed external temperature effect is supported by the correlation and residual drug effect results, and, in the absence of a cumulative drug effect, could account for all the variation found in the step test.

Thanks are due to Professor Slaney and Mr. F. Ashton for allowing us to study their patients, and to Dr. G. Malone, Staff Nurse R. Arnold, and Mrs. M. Cochrane for their assistance. The staff of the Pharmacy and Departments of Biochemistry and Haematology, Queen Elizabeth Hospital, Birmingham, played a valuable part. Pyridinolcarbamate levels were measured by Mrs. D. Dunkerley. Dr. J. Nelms helped with the design and loan of physiological equipment. Financial support was provided by Banyu Pharmaceutical Co., Tokyo, and Imperial Chemical Industries. G.M.C. was the recipient of a British Heart Foundation Research Fellowship. Finally we thank the patients for their co-operation and enthusiasm, which enabled the work to be completed.

\section{References}

Bloor, K. (196I). Natural history of arteriosclerosis of the lower extremities. Annals of the Royal College of Surgeons of England, 28, 36.

Bollinger, A., Simon, H. J., and Mahler, F. (1969). The natural course of peripheral arteriosclerosis obliterans evaluated by flow measurements. Angiology, 20, 414.
Burch, G. E., and DePasquale, N. P. (1963). Bradykinin. American Heart fournal, 65, 116.

Chamberlain, M. J., and Gleeson, J. A. (1965). Aortography in the investigation of hypertension. Lancet, 1, 619.

Craig, G. M., and Walton, K. W. (1972). Clinical trial of methyl clofenapate (a derivative of clofibrate) in patients with essential hyperlipidaemias, with special reference to type II (primary) hyperlipidaemia. Atherosclerosis, 15, 189.

Dawson, J. M., and Raphael, M. J. (1968). Serial aortography in the study of peripheral vascular disease - a clinicalradiological study. British fournal of Radiology, 41, 333.

Dedichen, J., and Vystyd, J. (1969). Kininase activity of plasma from patients with arteriosclerosis, diabetes and hepatitis. Scandinavian fournal of Clinical and Laboratory Investigation, 24, Suppl. 107, 125.

Eriksson, U. (1969). Effects of bradykinin, acetylcholine, and histamine upon the blood flow of the amputation stump of leg amputees. Scandinavian fournal of Clinical and Laboratory Investigation, Suppl. 107, 129.

Jackson, J. V., and Moss, M. S. (1969). Glutarimides and other neutral drugs. In Chromatographic and Electrophoretic Techniques, 3rd ed., Vol. I, p. 53I. Ed. by I. Smith, Heinemann, London.

Kjellmer, I. (1965). The potassium ion as a vasodilator during muscular exercise. Acta Physiologica Scandinavica, 63, 460.

Lykke, A. W. J., Willoughby, D. A., and Kosche, E. R. (1967). Thymic permeability factor: its relationship to lymphnode permeability factor and its antagonism by pyridinolcarbamate (anginin) and other anti-inflammatory agents. Fournal of Pathology and Bacteriology, 94, 38r.

Mellander, S., Johansson, B., Gray, S., Jonsson, O., Lundvall, J., and Ljung, B. (I967). The effect of hyperosmolarity on intact and isolated vascular smooth muscle. Possible role in exercise hyperaemia. Angiologica, 4, 310.

Piper, P. J., and Vane, J. R. (I969). Release of additional factors in anaphylaxis, and its antagonism by anti-inflammatory drugs. Nature (London), 223, 29.

Pratesi, F. (1972). Effect of pyridinolcarbamate in the treatment of arterial and venous diseases. Experimental and clinical report. In Tokyo Conference on Atherogenesis, Thrombogenesis and Pyridinolcarbamate Treatment, 1972. Excerpta Medica, Amsterdam. In the press.

Rodbard, S., and Pragay, E. B. (1968). Contraction frequency, blood supply, and muscle pain. Fournal of Applied Physiology, 24, 142.

Shepherd, J. T. (1950). The blood flow through the calf after exercise in subjects with arteriosclerosis and claudication. Clinical Science, 9, 49.

Shimamoto, T., Atsumi, T., Yamashita, S., Motomiya, T., Isokane, N., Ishioka, T., and Sakuma, A. (1970). Clinical pharmacologic evaluation of the antiatherosclerotic agent, pyridinolcarbamate. A double-blind crossover trial in the treatment of atherosclerosis obliterans. American Heart Fournal, 79, 5 .

Shimamoto, T., Sasaki, T., Fujita, T., and Mukai, N. (r966a). The natural history of atherosclerosis: comparison of aortic lesions in Tokyo, New Orleans, Guatemala and Costa Rica. Fournal of Atherosclerosis Research, 6, ro7.

Shimamoto, T., Maezawa, H., Yamazaki H., Atsumi, T., Fujita, T., Ishioka, T., and Sunaga, T. (I966b). Pyridinolcarbamate, a bradykinin antagonist in veins. American Heart fournal, 71, 297.

Silbert, S., and Zazeela, H. (1958). Prognosis in arteriosclerotic peripheral vascular disease. Fournal of the American Medical Association, 166, 1816.

Sternieri, E., Mucci, P., Bertolini, A., and Castelli, M. (1969). Variazioni stagionali nella sensibilita alla bradichinina del coniglio e del ratto. Bollettino della Società Italiana di Biologia Sperimentale, 45, 421. 
Tillgren, C., and Lund, F. (1967). Spontaneous course of various clinical types of obliterative arterial disease of the legs. Scandinavian fournal of Clinical and Laboratory Investigation, 99, Suppl. I 54.

Walton, K. W. (1969). The biology of atherosclerosis. In The Biological basis of medicine, Vol. 6, p. I93. Ed. by E. E. Bittar and N. Bittar. Academic Press, London.

Whitehead, T. P. 1969). The computer in the laboratory. Practitioner, 203, 294.

Whitney, R. J. (1953). Measurement of volume changes in human limbs. Fournal of Physiology, 121, I.
Willoughby, D. A., Lykke, A. W. J., and Ryan, G. B. (1969). A study of the anti-inflammatory action of pyridinolcarbamate (Anginin). In Atherogenesis, p. 133. Ed. by T. Shimamoto, F. Numano, C. N. Hales, and A. Perrin. Excerpta Medica Foundation, Amsterdam.

Requests for reprints to Professor K. W. Walton, Department of Experimental Pathology, Rheumatism Research Wing, The Medical School, Birmingham BI5 2TJ. 